\title{
PROSTHESIS, TECHNOLOGY AND TRAUMA IN THE MACHINIST FETISHES OF OMA'S VILLA AT BORDEAUX
}

\author{
MICHAEL CHAPMAN \\ School of Architecture and the Built Environment \\ University of Newcastle, Callaghan \\ University Drive, Callaghan, NSW 2308, Australia
}

Michael.Chapman@newcastle.edu.au

\section{MICHAEL OSTWALD}

School of Architecture and the Built Environment University of Newcastle, Callaghan

University Drive, Callaghan, NSW 2308, Australia

Michael.Ostwald@newcastle.edu.au

\begin{abstract}
The paper will look at the historical notion of prosthesis through an analysis of Rem Koolhaas's 1998 House at Floirac where technology becomes the literal and spiritual generator of the space mediating, through architecture, the uneasy collision between the body and the machine. Organised around a centralised passenger lift for the wheelchair bound owner of the house, and enveloped by the associated family spaces, the house is a highly calibrated architectural object which supplements the body and its internal desires, while at the same time being dependent upon it for its programmatic completion. In the House at Floirac technology is problematised as competing internal and external programmes which a spatial conversation between the sky and ground. The paper will explore the themes embedded in the spatial programme of the House at Floirac by connecting it with the broader theoretical speculations of OMA and a cultural history of prosthetics. Read as an extension of Koolhaas's gendered observations of the architecture of Manhattan, and eroticised speculations in "Strategy of the Void", the House at Floirac is evidence of a much deeper strand in OMA's work through which technology and the body are entwined.
\end{abstract}

Keywords: OMA, Rem Koolhaas, Prosthesis, Sigmund Freud, Psychoanalysis

\section{Introduction}

The problematic nexus between architecture, the body and the machine, first framed in the Enlightenment by the prosthetic imagery of Piranesi and Diderot, has been a favourite theme of avant-garde practices throughout the Twentieth Century, but particularly in the tumultuous interwar period. Representing a consistent trope in the writings of Surrealism and drawing indiscriminately from the work of Sigmund Freud, technology is positioned as a prosthetic "trauma", which mediates the relationship between the body and architectural space through a 
host of sexually originating psychoanalytical fantasies such as castration, seduction and the intrauterine. Accompanying these practices was a new cinematic regime where the body, the machine and the architectural volume were intimately connected as the nomadic agents of visual experience.

This paper will look at the way that a resurgence of these avant-garde practices can be read in the recent work of OMA, and specifically in the widely published House at Floirac (known also as the Maison á Bordeaux). Drawing from recent investigations in art theory, the paper will demonstrate how the House at Floirac is representative of a much broader architectural manifesto that, while not consciously articulated in the texts of Koolhaas, is inscribed in the work of OMA. This hidden programme seeks to problematise the relationship between architecture and technology by internalising the machinist logic of modernism and establishing highly eroticised connections between the architectural object and the human body. In the House at Floirac, technology becomes the interface between the living body and space, directly implicated in its protection and gratification as well as its marginalisation and exclusion. Throughout the house technology is articulated programmatically as a spatial exchange between substance (the material) and absence (the void).

\section{House at Floirac and the prosthetics of programme}

Since the early eighties OMA has concerned itself obliquely with the artistic resolution of the problems of the house. While recognised for their urban projects, the House at Floirac is only the most recent in a series of highly refined residential dwellings which sit on natural sites, with expansive views, removed from urban "congestion", and surrounded, in many instances by nature. Completed in 1998 on the rolling hills surrounding the French city of Bordeaux, the $500 \mathrm{~m}^{2}$ House at Floirac responds aggressively to the internal complexities of a steeply sloping site, the idiosyncratic requirements of the client and, more discreetly, to the overwriting intellectual themes that have governed OMA's expanding body of architectural work across the last 30 years. In each of these categories, the external programmatic desires are mediated through an internalised order of technology, resisting gravity, domesticity and, most violently of all, the historical bond between form and programme. In this way the house uses technology to create an intimate connection between the architectural object and the bodies that inhabit it. It functions, in the historic sense, as a prosthetic, enabling and enhancing the body/inhabitant, but at the same time constraining it.

The story of the commission for the House at Floirac is well known: originally commissioned by a married couple, the husband (after the initial commission) had a serious car accident which confined him to a wheel chair. The house was, as a result, designed around this altered brief, to create a space of freedom and versatility where the husband would be assured maximum mobility and access to the dramatic views that surrounded the site. As a result the House at Floirac is organised around an internal platform lift $(3 \mathrm{~m} \times 3.5 \mathrm{~m})$ which functions as a movable office (what Koolhaas calls a 'station') and allows him access to the various levels of the house as well as the three-storey storage wall which houses his books, artwork and wine cellar. Around this diagram, three separate levels are arranged. The ground floor, carved out from the rock on one side, houses parking, kitchen, servant and guard spaces. Koolhaas describes this residual level as "cave-like-a series of caverns carved out from the hill for the most intimate life of the family" $(2000,54)$. The middle floor, an extended living zone, is largely transparent with operable glazed partitions opening onto an expansive deck area. Above is an enclosed box, punctured with scattered glass portholes. The floating steel box houses separate dwellings for both parents and children, or in Koolhaas's words: "a house for the couple and a house for the children" $(2000,54)$. The final line of Koolhaas's short narrative text for the house is the widely quoted epigram "a machine was at its heart." The line has been central to almost all writing on the house, both theoretical and otherwise.

A vast array of spatial strategies connect the House at Bordeaux with a broader culture of psychoanalysis. The striated family home, separated from servants, is divided in its nature between children, mother and father in a concentric oedipal configuration. The house is also, as Dovey (2002) has illustrated, patriarchal in nature, giving unprecedented architectural supremacy to the male father figure despite his disability. While there are four separate vertical circulation stacks in the house, the central lift, which becomes an office, study and viewing platform for the wheelchair-bound father, takes spatial predominance and creates an internalised male sanctuary within the broader envelope of the family. To control the centre is thus to displace the father. There is also a mythic dimension to the way the house nests its "earthy", wet spaces in the ground, creating a clear, transparent internal platform and an ornamental floating box above. The box, floating in the sky, becomes the symbolic face for the 
building, while the internal plumbing is nested deeply in the bowels. Servicing, servants, kitchens and residual activites like storage and parking are contained on the lower level. Living, is contained in the transparent intermediate zone with commanding views of the surrounding area. The elevated box, punctured with carefully positioned visual openings, becomes the place for sleeping, dreaming and the unconscious. These three stratified zones comply to widely held polarities in psychoanalysis such as ground/sky, solid/void, conscious/unconscious, wet/dry, visual/sensual and indirectly, male/female. Technology, manifested in the inner hydraulic platform (connected through telecommunications to the broader world) and the externalised structure which constrains them-is the physical and conceptual connection that links these conflicting poles of psychic space.

Koolhaas, as well known for his charismatic texts as for his buildings, has remained conspicuously silent on the question of the house and its relationship to his work. As Koolhaas said famously of Manhattan $(1977,9)$ the residential projects of OMA can be read as "evidence without manifesto"-idiosyncratic obsessions unadorned by any conscious or deliberate text or polemic that accompanies and justifies the architectural objects and their spatial arrangement. While Koolhaas has accumulated a vast and expanding written oeuvre addressing the way that architects should engage with the problems of the city, the relationship of the home, the house and the family remain untheorised. As Bart Verschaffel $(2003,161)$ points out, not only are terms such as "house" omitted from the expansive glossary of quotes that runs continuously across the length of $S, M, L, X L$ but photographs of the intimate, central spaces of the completed houses are rarely revealed. This absence creates a "void" in Koolhaas's otherwise consuming rhetoric about the function of architecture and its relationship to the broader urban projects of OMA. Verschaffel attributes this silence to a Roman "withdrawal" from society where the houses function like Palladian Villas as a (untheorised) respite from the hectic life of the Roman city, or, in this case, the highly publicised urban projects, of OMA. For Verschaffel, the silence guarantees an autonomy and independence for the houses, freeing them from the theoretical constraints of the practice as well as the intrusive spectre of publicity. While this "creative respite" explains in part the apparent omission of a theoretical attitude towards the house in OMA's work, this paper will argue that the projects, and in particular the House at Floirac, represent an important arm of OMA's creativity and, in Koolhaas's terms, constitute a kind of "petri-dish" where the broader intellectual themes of the practice are expanded and articulated. The House at Floirac can be read as evidence: a manifestation (or even crystallisation), in a highly specific architectural sense, of the overwriting themes-technology, the interior and the centre/void-that have predominated over the last 30 years of OMA's creativity. Rather than a withdrawal, the house in OMA's work represents an internal laboratory where the body and the architectural machine are placed in a state of perpetual crisis.

\section{Prosthetics: the machine, the body and the mechanical heart}

Writing in 1992, before the commission for the House at Floirac had even arrived, Spanish critic Alexandro Zaera (1992, 6-31) wrote that:

"OMA's recent projects [...] constitute bodies rather than objects. Body in the sense of material without linguistic overcoding; neither pure nor fragmentary forms, but vague essences: rounded, elongated, oblong [...]. No more constants, no more ideal forms, nor their fragments but instead their deformations".

The observation, repeated in $S, M, L, X L(66)$ under the glossary title "bodies", is made explicit in Koolhaas's accompanying text for the House at Floirac. By insisting that "a machine was at its heart", Koolhaas renders the house anthropomorphic (through the possession of a heart) as well as prosthetic (through the machinery which proliferates it). As the machinery of the house becomes "human", the human inhabitant is equally symbiotically connected with machinery, firstly his wheelchair, and then the lift which controls his access, and the access of others to the house. While the focus on the "machine" has been central in many analyses, it is the way that the "body" interacts with this machine that is revealing of a deeper ancestry. It has immediate associations with prosthetics and the complex Twentieth Century history of humans, machines and the spaces that enclose them, in particular those of the house.

Anthony Vidler has argued on a number of occasions $(1990,2006)$ that a transition occurs over the course of the Twentieth Century from the constructed humanist body (present from Vitruvian Classicism to the high Modernism of Le Corbusier) to the psychological or pyschoanalytical body which, rather than being the idealised inhabitant of architectural space, is transformed into the constructing body, which shapes spaces through its insecurities, phobias and compulsive disorders. This schema of the body was explored widely in Surrealism, particularly through 
effects of photography and film. The House at Floirac accelerates this 1920 s view of prosthetics, to the point where the architectural envelope and the human body become seamlessly entwined and symbiotically dependent on each other. The body completes the architecture as much as the architecture enhances the body. Programme is constructed as a prosthetic to architectural space, enhancing and enabling, but also infiltrating its autonomy. With the evolution of technology, the nature and awareness of this "prosthetic armature" is increasingly less visible, to the point where its operations are so discreet that they can be silently embedded within the body or the architectural envelope which encloses it. They are no longer supplementary, but part of the physical material and psychological substance of architecture and the body. In Floirac, this relationship is dramatised. As Beatriz Colomina wrote, following her visit to the house in 1998

"The ideal client of modern architecture, the culmination of a century of research, is a wheelchair bound body, mechanised in its movements, fully connected to cyberspace. The free section extends seamlessly into the internet." (45)

The House at Floirac, while locating a machine at its heart, is at the same time creating a void, or an empty space fulfilled only by a silent technology. The human body, no longer adequately equipped to experience the house, becomes supplemented by the technology of the lift, and, in the process submissive to it. The moving hydraulic lift controls the space in plan and section filling the central spaces of the sleeping quarters, living space and domestic kitchen when it is in place, and creating a void, unprotected by balustrades, when it, and the father, is absent. The father's body is dependent on the lift for mobility, and the house itself is dependent on the presence of the father's body for stability or completeness. The prosthetic machinery of the house in this way acts as a supplement not only to the father (allowing him exclusive access to his most intimate possessions), but also his marriage (completing the floorplate of the couples sleeping quarters) and, most dramatically of all, the family (functioning as the central zone of the living quarters and as an empty void when the father is absent or elsewhere in the house).

The structure of the house is equally prosthetic, celebrating the house's vulnerability rather than its stability. Poised dramatically on an oversized column and beam at one end (the parents), and delicate cable connection at the other (the children), the support of the floating box creates a dialogue of push/pull; compression/tension. If the cable is to snap, as engineer Cecil Balmond reveals in his notes for the structure $(2002,30)$ the box will tilt precariously; not enough to collapse, but to remain in a state of perpetual instability until the cable is reinstalled. Despite the simplicity of the box floating above the landscape, the harsh complexity of the technology that locates, positions and ultimately impales the box is indiscreet and, throughout its operation invasive in its relationship to the body and space.

Where the mechanical (moving) technology of the house is internalised, the structural (static) technology of the house is dramatised creating a complex dialogue between interior and exterior. The mechanical celebrates gravity, the structural resists it. In each case these technologies are positioned against their opposite. In the structure, stability is architecturally married with the drama of collapse. In the mechanical lift core the presence of the moving platform which connects the house, is equally experienced against the hole created by its absence. In each case the body is made aware of its prosthetic nature, enabled through movement but paralysed through collapse. It is through this diagram that technology is articulated not as the substance of architecture (its material), but as the absence of architecture (the void).

\section{Technology and the Interior: Voids and Cavities in the spatial strategies of OMA}

The relationship between substance and absence which underpins the technological schema of the House at Floirac is, rather than an isolated fetish, a central motif in the work of OMA and in the writings of Koolhaas in particular. While difficult to historicise, the gymnastic nature of OMA's practice over the last 30 years has moved from the obsessively programmatic (embodied in the canonical urban plans of Melun-Sert and the Parc de la Villette of the early 80 s) to the relentlessly formalistic (recognisable in the more recent programmatic ambivalence, such as the seamless transition from House $\mathrm{Y} 2 \mathrm{~K}$ to the Casa de Musica). Within this is an attitude towards technology that is, for the most part consistent and, at the same time, radically polemical in its relationship to modernity. The themes embedded in the House at Floirac, as well as responses to an idiosyncratic problem of housing, can equally be positioned in a much broader intellectual context, informed by Koolhaas's writings on the city, and inherently embedded in the primary conceptual preoccupations of the practice. 
Koolhaas's fascination with technology was first articulated in his 1978 book Delirious New York. Koolhaas's retro-active manifesto for Manhattan was based intrinsically on the logic of the passenger lift and the programme of the repetitive grid, advocating a bustling, imperfect urbanism where blocks are transformed into competing city-states by the spatial autonomy of vertical movement. Koolhaas linked the architecture of Manhattan to the surgical processes of the "lobotomy" whereby the outer skin of the building is freed from its internal programme. The passenger lift enabled a "vertical schism" where independent floors could be isolated and used for a range of programmatic activities unconstrained by activities above or below them and independent of the expression of the external façade. This programmatic separation between the interior (services) and the exterior (clothes) of the building is inherently related to anthropomorphic readings, from the "surgical" analogies that Koolhaas' uses to describe it to the metaphorical association between city blocks and soldiers, aggressively poised in potential combat.

However the connection between bodies and the internal schema of Manhattan, is at its most eccentric in Koolhaas's account of the Architect's Ball in Delirious New York, originally published in Oppositions (1974). Here the dialectic between external clothing and internal servicing is expressed literally through the extravagant costumes which saw leading architects come dressed as the iconic buildings they had designed, comprising a literal human army of high-rise buildings documented unemotionally in a sober press photo from the time. The only feminine representative amongst the collection of men is, as Koolhaas points out, the "basin girl" who:

carries a basin as an extension of her belly; two taps seem even further entwined with her insides. An apparition straight from the men's subconscious, she stands there on the stage to symbolise the entrails of architecture, or, more precisely: she stands for the continuing embarasssment caused by biological functions of the human body that have proved resistant to lofty aspirations and technological sublimation. (157)

This technological schema that is articulated in the House at Floirac was central throughout Koolhaas's analysis of New York: torn between competing impulses of structural defiance and biological necessity. The prosthetic relationship implied in the observations on the Architect's Ball is a crisis played out between ostentatious external expression and convoluted internal conceit. This spatial "labotomy" separates the necessities of technology at the interior from the external architectural expression creating a clear dialogue between interior/exterior and up/down. Koolhaas returns to the "masculine" struggle against gravity $(1978,158)$ in his discussion of the Downtown Athletic Club where verticality, enabled by technology, has lifted the well-toned Metropolitanites "beyond the reach of fertile brides". In a moment of Nietzschean candour Koolhaas writes "the men are on a collective 'flight upward' from the Spectre of the Basin girl."

These two competing, gendered and overtly simplified technologies, one upward towards the sky and the other downward towards the ground, are replete throughout the work of Koolhaas and explicit in the House at Floirac. Already present in Strategy of the Void, OMA's unsuccessful competition entry for the Paris Biblioteque, Koolhaas connects the relationship between positive and negative space with explicitly sexual imagery. The image which introduces the project in $S, M, L, X L$ is a sexualised image, where the male genitalia is replaced with a void, a manufactured "gap" in the image screen. This omission or censure (observed by Whiting $(1999,52)$ in her interview with Koolhaas as a "very one directional eroticism") is descriptive of the project where the solid spaces are inverted, becoming in themselves cavities. Public space is conceived as an "absence of building" in an otherwise continuous block of information and technology.

The erotic nature of Koolhaas's work in well known. Kipnis describes his model of dismantling conventional programmes as "[m]ore like a sadist than a surgeon" $(1998,29)$ and Matthew Stadler considers him "our most profoundly carnal architect" (127). For Stadler, Koolhaas's work should not be read theoretically, but phenomenologically, through the experiences and implied sexuality of the spaces and programmes. This is a theme in critical accounts of the House at Floirac which have isolated the "gendering" of its spaces, explicit in Koolhaas's own terminology: "the man had his own 'room"' which contained everything the "husband" might need. Dovey points out that while the programme is not inherently chauvinistic (a female could occupy the lift space) it does make the lift intrinsic to the power structures which underpin the spatial programme. The perceived gendering of space is further confirmed by its isolated inclusion in Joel Sander's work Stud: The Architectures of Masculinity which implies a connection with the bachelor pads of the 1960s portrayed in Playboy magazine, where the cavities of walls became the embodiment of technology (from hi-fi equipment to rotating beds). 
Sanders describes the House in Floirac briefly as a "prosthetic architecture" where the central male occupant is granted "visual and physical freedom, attributes necessary for the successful performance of masculinity." (21)

While these gendered themes in the house are pervasive, they are embedded in a much more complex schema of technology. The dialectic that Koolhaas establishes in Manhattan and hypothesises in Strategy of the Void is not so much between male and female, but between the technologies of structure (exterior) and biological mechanics (interior), effectively displaced by the spatial "lobotomy" that sees the programme and its expression disconnected. This dialectic between substance /absence, solid/void achieves its most lucid diagrammatic expression in the House at Floirac where the mechanical and structural technologies that underpin the house are effectively dramatised as the internal and external expression of the building, harmoniously complementing the vertical aspirations of the programmes they encompass. Expressed metaphorically as a complex labyrinth of family life, striated between earthy, residual spaces below and elevated floating spaces above, the house embodies these competing aspirations towards sky and ground. The technological umbilical cord of the central patriarchal lift becomes the passage into and out of this internalised labyrinth, functioning as a "prosthetic" against the castrative effects of the internal programme and enabling the human body to engage with the architectural envelope and, at the same time, escape from it. At Floirac, architecture is expressed as this exchange between competing prosthetic technologies into which the human body and its associated desires are irrevocably sandwiched.

It is within the context of Koolhaas's theoretical speculations, and a historical notion of prosthesis, that the relationship between the body, architecture and technology in the House at Floirac can be conceptualised. Constituting an internalised prosthetic, the boundaries between architecture and the body at the House at Floirac become irrevocably displaced by the competing technologies which position it. Rather than an isolated intellectual speculation, the themes embodied in the spatial programme of the House at Floirac are part of an internalised trajectory that has been central to the architecture and research of Koolhaas, and the Office for Metropolitan Architecture.

\section{References}

Balmond, Cecil, and Januzzi Smith. Informal. Munich: Prestel-Verlag, 2000.

Colomina, Beatriz and Blanca Lleo. "A Machine was Its Heart: House in Floirac." Assemblage 37 (December 1998): 36-45.

Dovey, Kim, and Scott Dickson. "Architecture and Freedom: Programmatic Innovation in the Work of Koolhaas/Oma." Journal of Architectural Education 56 (1) (2002): 5-13.

Kipnis, J. "Recent Koolhaas." El Croquis 79 (1998): 26-31.

Whiting, Sarah. "Spot Check: A Conversation between Rem Koolhaas and Sarah Whiting." Assemblage 40 (December 1999): 36-55.

Koolhaas, Rem. "The Architects' Ball—a Vignette." Oppositions 3 (May 1974): 91-96.

Koolhaas, Rem. "Maison á Bordeaux." A+U: OMA@work (May 2000: Special Issue): 54-65.

Koolhaas, Rem. Delirious New York: A Retroactive Manifesto for Manhattan. New York: The Monacelli Press,1978.

Koolhaas, Rem. S,M,L,XL. Rotterdam: 010 Publishers, 1995.

Lavin, Sylvia. Form Follows Libido: Architecture and Richard Neutra in a Psychoanalytic Culture. Cambridge: The MIT Press, 2004.

Sanders, J., Ed. Stud: Architectures of Masculinity. New York, Princeton Architectural Press, 1996.

Stadler, M. "The Story of K." In V. Patteeuw ed. What is OMA: Considering Rem Koolhaas and the Office for Metropolitan Architecture. Rotterdam, NAi Publishers, 2003: 123-135.

Verschaffel, Bart. "The Survival Ethics of Rem Koolhaas: The First Houses by Oma." In V. Patteeuw ed. What is OMA: Considering Rem Koolhaas and the Office for Metropolitan Architecture. Rotterdam, NAi Publishers, 2003: 153-64.

Vidler, Anthony. "The B-B-B-Body: Block, Blob, Blur." In Deborah Hauptmann, ed. The Body in Architecture. Rotterdam: 010 Publishers, 2006: 130-37. 
Vidler, Anthony. "The Building in Pain: The Body and Architecture in Post-Modern Culture." AA Files 19 (Spring 1990): 3-10.

Vidler, Anthony. The Architectural Uncanny: Essays in the Modern Unhomely. Cambridge: The MIT Press, 1992.

Vidler, Anthony. Warped Space: Art, Architecture and Anxiety in Modern Culture. Cambridge: The MIT Press, 2000.

Wigley, Mark. "Prosthetic Theory: The Discipline of Architecture." Assemblage 15 (August 1991): 6-29.

Zaera, A. and R. Koolhaas. "Finding Freedoms: Conversation with Rem Koolhaas." El Croquis 53 (1992): 6-31.

Zaera, Alejandro. "Notes for a Topographic Survey." El Croquis 53, no. OMA 1986-1991 (March 1992): 32-51. 